\title{
Detection of Canonical Hedgehog Signaling in Breast Cancer by 131-Iodine-Labeled Derivatives of the Sonic Hedgehog Protein
}

\author{
Jennifer Sims-Mourtada, ${ }^{1,2}$ David Yang, ${ }^{3}$ Izabela Tworowska, ${ }^{2}$ Richard Larson, ${ }^{4}$ \\ Daniel Smith, ${ }^{4}$ Ning Tsao, ${ }^{3}$ Lynn Opdenaker, ${ }^{5}$ Firas Mourtada, ${ }^{1,4}$ and Wendy Woodward ${ }^{4}$ \\ ${ }^{1}$ Helen F. Graham Cancer Center, Christiana Care Hospital, Newark, DE 19713, USA \\ ${ }^{2}$ RadioMedix, Inc., Houston, TX 77042, USA \\ ${ }^{3}$ Department of Experimental Diagnostic Imaging, The University of Texas MD Anderson Cancer Center, Houston, TX 77030, USA \\ ${ }^{4}$ Department of Radiation Oncology, The University of Texas MD Anderson Cancer Center, Houston, TX 70030, USA \\ ${ }^{5}$ Department of Biological Sciences, University of Delaware, Newark, DE 19716, USA
}

Correspondence should be addressed to Jennifer Sims-Mourtada, jsimsmourtada@christianacare.org

Received 29 February 2012; Revised 23 April 2012; Accepted 7 May 2012

Academic Editor: Lie-Hang Shen

Copyright ( $(2012$ Jennifer Sims-Mourtada et al. This is an open access article distributed under the Creative Commons Attribution License, which permits unrestricted use, distribution, and reproduction in any medium, provided the original work is properly cited.

\begin{abstract}
Activation of hedgehog $(\mathrm{HH})$ pathway signaling is observed in many tumors. Due to a feedback loop, the HH receptor Patched (PTCH-1) is overexpressed in tumors with activated HH signaling. Therefore, we sought to radiolabel the PTCH-1 ligand sonic $(\mathrm{SHH})$ for detection of cancer cells with canonical HH activity. Receptor binding of ${ }^{131} \mathrm{I}-\mathrm{SHH}$ was increased in cell lines with high $\mathrm{HH}$ pathway activation. Our findings also show that $\mathrm{PTCH}-1$ receptor expression is decreased upon treatment with $\mathrm{HH}$ signaling inhibitors, and receptor binding of ${ }^{131} \mathrm{I}-\mathrm{SHH}$ is significantly decreased following treatment with cyclopamine. In vivo imaging and biodistribution studies revealed significant accumulation of ${ }^{131} \mathrm{I}-\mathrm{SHH}$ within tumor tissue as compared to normal organs. Tumorto-muscle ratios were approximately $8: 1$ at 5 hours, while tumor to blood and tumor to bone were $2: 1$ and $5: 1$, respectively. Significant uptake was also observed in liver and gastrointestinal tissue. These studies show that ${ }^{131} \mathrm{I}-\mathrm{SHH}$ is capable of in vivo detection of breast tumors with high $\mathrm{HH}$ signaling. We further demonstrate that the hedgehog receptor PTCH-1 is downregulated upon treatment with hedgehog inhibitors. Our data suggests that radiolabeled SHH derivatives may provide a method to determine response to $\mathrm{SHH}$-targeted therapies.
\end{abstract}

\section{Introduction}

The association between the hedgehog $(\mathrm{HH})$ pathway and cancer was initially established by the identification of heterozygous mutations affecting the membrane receptor PATCHED-1 (PTCH-1), resulting in abnormal activation of $\mathrm{HH}$ signaling in basal cell carcinoma and neural tumors $[1,2]$. Recently, several studies have shown ligand-dependent constitutive activation of the $\mathrm{HH}$ signaling pathway in many solid tumors including prostate, breast, ovarian, esophageal, gastric, and lung cancers. Sonic ( $\mathrm{SHH}$ ) ligand secreted from tumor cells can have a growth-promoting effect on both tumor and stroma cells [1-7]. Furthermore, HH signaling has been implicated in resistance to radiation and chemotherapy through regulation of survival proteins, cell cycle, DNA repair, and drug transport [8-10]. A recent report demonstrated that $\mathrm{HH}$ signaling can impair ionizing radiation-induced checkpoints, resulting in increased survival and genomic instability following radiation therapy [11].

Canonical activation of $\mathrm{HH}$ activity occurs when secreted SHH binds to and inhibits the cell surface receptor PTCH1. This binding relieves the PTCH-1-mediated suppression of the transmembrane protein SMOOTHENED (SMO) leading to multiple intracellular events that result in the stabilization, nuclear translocation, and activation of the Gli family of transcription factors (Gli-1, 2, and 3) [12, 13]. Transcriptional targets of Gli include genes controlling cell cycle, cell adhesion, signal transduction, vascularization, and apoptosis [14]. PTCH-1 is also a target of this pathway 
[15], providing feedback for $\mathrm{HH}$ signaling. Thus, PTCH-1 expression is increased on cells with active $\mathrm{HH}$ signaling.

PTCH-1 is overexpressed in many epithelial-derived cancers, when compared to adjacent normal tissue, and its expression is usually correlated to overexpression of other $\mathrm{HH}$ pathway members. Immunohistochemical analysis of breast carcinomas revealed overexpression of SHH, PTCH-1, and Gli-1 in breast cancer specimens, compared to adjacent normal tissue [16]. Expression of HH pathway members in breast cancer has been shown to correlate with progesterone receptor expression, high proliferative index of Ki67 lymph node metastasis and clinical grade $[16,17]$.

Inhibition of $\mathrm{HH}$ signaling in animal models of cancer has shown promising effects. Currently, multiple classes of $\mathrm{HH}$ inhibitors are under clinical development at several major pharmaceutical companies [18]. However, there is presently no noninvasive method to screen for potential candidates who may benefit from $\mathrm{HH}$-targeted therapies or to follow inhibition of $\mathrm{HH}$ signaling in vivo. Here, we report the synthesis and characterization of an iodinated derivative of SHH that targets $\mathrm{PTCH}-1$ receptor expression. This approach has several advantages for imaging of $\mathrm{HH}$ expression. One, there is a feedback loop that results in increased transcription and membrane localization of PTCH-1 in cells with active HH signaling [15]. Additionally, the $\mathrm{N}$-terminal fragment of $\mathrm{SHH}$ is internalized by receptormediated endocytosis of the PTCH-1 receptor. The degree of receptor internalization has been associated to the levels of active $\mathrm{HH}$ signaling [19].

\section{Materials and Methods}

2.1. Cell Lines and Antibodies. Human breast cancer cell lines were obtained from ATCC and cultured in Dubelco's modified eagles media, supplemented with $10 \%$ (vol:vol) fetal bovine serum and $1 \%$ antibiotic-antimycotic at $37^{\circ} \mathrm{C}$ in a humidified atmosphere containing $5 \%$ carbon dioxide. The rat breast cancer cell line 13762 was derived from a tumor induced in Fischer-344 rat by giving an oral dose of 7,12dimethyl-benz[a] anthracene [20]. The cells were cultured in RPMI-1640 medium, supplemented with 10\% (vol:vol) fetal bovine serum and $1 \%$ antibiotic-antimycotic at $37^{\circ} \mathrm{C}$ in a humidified atmosphere containing 5\% carbon dioxide. Cyclopamine was obtained from LC labs. Cells were treated with $10-40 \mu \mathrm{M}$ cyclopamine resuspended in ethanol and diluted in normal culture media for the indicated time points. Control cells were treated with ethanol only. Gli1 (H-300), Patched-1 (C-20), and B-actin (C-2) antibodies were purchased from Santa Cruz Biotechnologies. Alexa555 and 488 secondary antibodies were purchased from Molecular Probes. HRP-conjugated secondary antibodies were purchased from Jackson Labs.

2.2. Protein Purification and Iodination. A recombinant derivative of the $19.5 \mathrm{kDa}$ human N-terminal SHH protein was purified from the E. coli strain BL21/DE3/PLysS (Stratagene, La Jolla, CA) expressing a pCOLDII vector (Genescript) that contains the wild-type cDNA encoding amino acid residues Cys 24 to Gly 197 of human SHH (accession number NP_000184) [21] linked to an N-terminal sequence encoding six consecutive histidine residues and an Asp-Asp-Asp-Asp-Lys enterokinase cleavage site. The SHH protein was purified using a nickel-based resin (Ni-NTA fast start kit, Qiagen), and resuspended in buffer containing $20 \mathrm{mM}$ phosphate, $150 \mathrm{mM} \mathrm{NaCl}$, and $0.1 \%$ Triton-X-100 pH 5.0. BSA protein (Sigma Aldrich) was used as a control and was resuspended in PBS at a $\mathrm{pH}$ of 7.4. The proteins were subsequently labeled with iodine-131 (Perkin Elmer) using the Iodogen method [22]. Briefly, 10-20 $\mu \mathrm{g}$ of protein was reacted with $\mathrm{Na}{ }^{131} \mathrm{I}$, (Perkin Elmer) in glass tubes precoated with 5-6 mg Iodogen (Sigma Aldrich) for 10-15 min at room temperature. The labeled proteins were purified using a sephadex P-10 column (Sigma Aldrich) preloaded with phosphate buffer $\mathrm{pH} 5.0$ or $\mathrm{pH}$ 7.4. Radiochemical purity was determined by radio-thin-layer chromatography (Waterman No. 1, Sigma-Aldrich), with $0.9 \% \mathrm{NaCl}$ as the eluant.

2.3. Western Blotting. Control or cyclopamine-treated cells were lysed with radioimmunoprecipitation assay (RIPA) buffer, and protein concentrations were determined using the BCA assay (Pierce). Western blot analysis using $40 \mu \mathrm{g}$ of protein was performed as previously described [23].

2.4. Immunofluorescence. Cells were fixed with methanol at $-20^{\circ} \mathrm{C}$ for $5 \mathrm{~min}$, washed twice with PBS, and blocked for 1 hour with $10 \%$ goat serum at room temperature. Antibodies were added at dilutions ranging from 1:50 to $1: 200$, overnight at $4^{\circ} \mathrm{C}$. Slides were washed 3 times with PBS and secondary antibodies were added at a dilution of 1:5000 for 1 hour at room temperature. Slides were washed $3 \mathrm{x}$ with PBS, and stained with Prolong Gold antifade reagent containing DAPI (Invitrogen). Slides were analyzed on a Zeiss AxioObserver Z1 Microscope, and images were processed using AxioObserver software. For analysis of nuclear Gli-1, 100 cells were counted per sample from three independent stainings. Cells were scored positive for nuclear Gli1 staining if they demonstrated intensive, predominantly nuclear Gli-1.

2.5. Cellular Proliferation Assay. Cells were seeded at a density of 5,000 to 10,000 cells per well in 96 well plates and grown overnight. Media was removed and replaced with culture media containing $10 \mu \mathrm{M}$ cyclopamine or ethanol. Cells were cultured for additional 48 hours, and proliferation was measured using the MTT-based cell proliferation assay (Biotinum).

2.6. Cellular Binding Assays. Cells were plated at a density of $50,000-100,000$ cells per well in 12 well plates and allowed to grow overnight. For inhibition studies, cells were treated with 10-20 $\mu \mathrm{M}$ cyclopamine or ethanol and allowed to grow for the indicated time. Culture media was removed and replaced with RPMI media containing $0.1-10 \mathrm{nM}{ }^{131} \mathrm{I}-\mathrm{SHH}$. Cells were grown for 1-2 hours, media was removed and collected and the cells washed 3 times with PBS and trypsinized. Media 


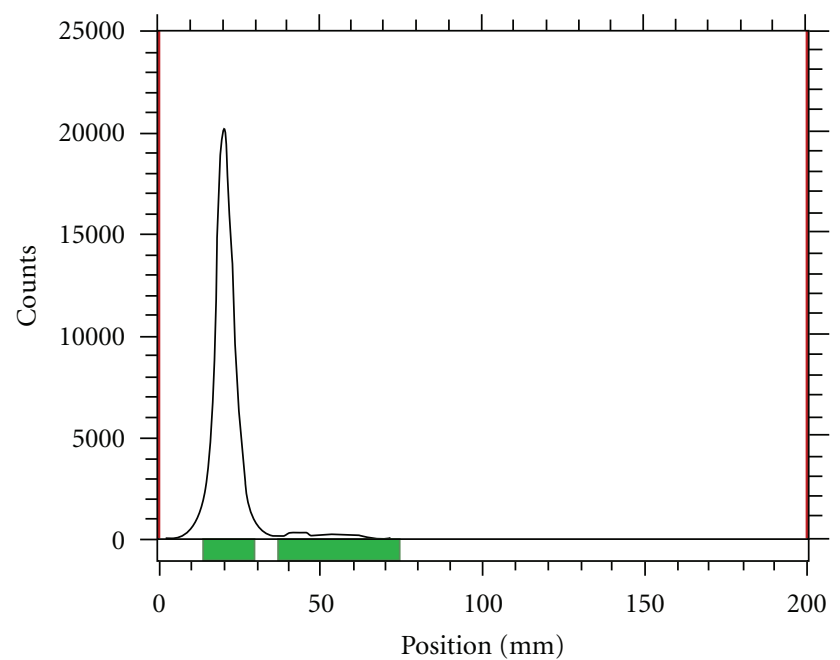

Figure 1: Radiochemical purity of $131 \mathrm{I}-\mathrm{SHH}$ was $>95 \%$. Radiochemical purity was determined by radio TCL with normal saline as the mobile phase.

and cells were counted in a gamma counter. Scatchard plots were generated using Graph pad software. Bmax (binding sites per cell) and $\mathrm{kD}$ were determined for each sample using data from three separate experiments. To control for specificity, cellular uptake studies were performed with 100fold excess unlabeled $\mathrm{SHH}$.

2.7. Animal Model. Six-week-old female Fischer 344 rats (150-175 g) (Harlan Sprague-Dawley, Inc., Indianapolis, IN) were used. Xenografts were generated from the rat mammary cell line 13762 by subcutaneous inoculation of 1 million cells in the right flank. Biodistribution and imaging studies were performed 10-14 days after inoculation when the tumors reached approximately $1-1.5 \mathrm{~cm}$ in diameter. All experiments were performed under authorization by the University of Texas MD Anderson Cancer Center Institutional Animal Care and Use Committee (IACUC).

2.8. Gamma Scintigraphy Studies. On the day of the study, rats were anesthetized with Isofluorane, and a tail vein cannula was inserted. Approximately $250 \mu \mathrm{Ci}$ of the radiolabeled tracer $\left({ }^{131} \mathrm{I}-\mathrm{SHH}\right.$ or $\left.{ }^{131} \mathrm{I}-\mathrm{BSA}\right)$ was delivered via tail vein injection. ${ }^{131}$ I images were acquired using a Siemens MCAM gamma camera with a high energy LP (HELP) collimator and a photopeak centered around $364 \mathrm{keV}$. Anesthetized animals were placed onto the camera, and counts were acquired for $10 \mathrm{~min}$. Images were acquired at $30 \mathrm{~min}, 1$ hour, 2 hours, 5 hours, and 24 hours following tail vein injection. Image files were saved in DICOM format and exported to Image J software (National Institute of Health, Bethesda MD) for further processing.

2.9. Biodistribution and Dosimetry Studies. Rats were anesthetized with Isofluorane, and a tail vein cannula was inserted. Approximately $20 \mu \mathrm{Ci}$ of the ${ }^{131} \mathrm{I}-\mathrm{SHH}$ was delivered via tail vein injection. In vivo biodistribution studies were performed at $0.5,2$, and 5 hours after intravenous administration of ${ }^{131} \mathrm{I}-\mathrm{SHH}$. Mice were sacrificed at the indicated time points $(n=3)$ and organs were excised. Organs were weighted, and radioactivity was counted in a gamma counter. Percent injected dose per gram was determined. Absorbed dose for each target organ was estimated using the OLINDA/EXM 1.1 software program (Vanderbilt University) with the adult male model. Rat biodistribution data were extrapolated to humans using an assumed rat weight of $150 \mathrm{~g}$ and the mass of each organ in the MIRD $70 \mathrm{~kg}$ adult male model as input to Equation 8 of AAPM Primer 71 [24]. Human organ time-activity curves were fitted to a monoexponential function using the OLINDA/EXM software to calculate individual organ residence times, from which the human dosimetry of ${ }^{131} \mathrm{I}-\mathrm{SHH}$ was then estimated.

\section{Results}

3.1. Radiolabeling. The SHH protein was radiolabeled with ${ }^{131}$ Iodine at specific activities up to $740 \mathrm{GBq} / \mathrm{g}$. Radiochemical yields of $40-65 \%$ were obtained. Radiochemical purity of $>95 \%$ was determined by radio-thin-layer chromatography, (Figure 1).

3.2. Cellular Binding Assays. Cell-binding studies were performed in breast cancer cell lines with varying $\mathrm{HH}$ pathway activity. Cellular uptake (Figure 2(a)) correlated with nuclear Gli-1 staining (Figure 2(b)) as well as PTCH-1 receptor expression (Figure 2(c)). Cell uptake increased over time and was blocked with 100 -fold excess cold $\mathrm{SHH}$ protein confirming receptor specificity (Figure $2(\mathrm{~d})$ ). To determine if the uptake ${ }^{131} \mathrm{I}-\mathrm{SHH}$ could be modified after $\mathrm{HH}$ signaling inhibition, we treated breast cancer cells with a 10-20 $\mu \mathrm{M}$ dose of cyclopamine, a commercially available SMO inhibitor [25]. As shown in Figure 3(a), cyclopamine treatment resulted in a significant decrease in proliferation, which is directly correlated with pretreatment Gli-1 levels. A decrease of PTCH-1 protein levels was observed after treatment with cyclopamine by western blotting and immunofluorescence (Figures 3(b) and 3(c)). Scatchard analysis revealed a fivefold decrease in surface PTCH-1 receptor expression after treatment with cyclopamine (Figure 3(d)). Consistent with these findings, a $50 \%$ reduction in uptake of radiolabeled $\mathrm{SHH}$ was observed in cells treated with cyclopamine (Figure 3(e)). These results suggest the potential to follow response to $\mathrm{HH}$ pathway inhibition using radiolabeled $\mathrm{SHH}$.

3.3. Biodistribution and Dosimetry Studies. Based on the baseline expression of $\mathrm{HH}$ signaling proteins and tumor growth characteristics, in vivo studies were carried out using xenografts from the rat mammary cell line 13762 in Fischer rats. The 13762 model was chosen due to its efficiency of tumor growth and its high canonical $\mathrm{HH}$ signaling, evidenced by high protein expression of PTCH and Gli-1 as well as the ligand (Figure 4). This cell line also demonstrated high in vitro uptake of the tracer. The results, shown in Table 1, reveal significant tumor uptake with tumor-tomuscle ratios of $8: 1$ at 5 hours, while tumor to blood and 
TABLE 1: Biodistribution of ${ }^{131} \mathrm{I}-\mathrm{SHH}$.

\begin{tabular}{|c|c|c|c|c|c|c|}
\hline \multirow[b]{2}{*}{ Organ } & \multicolumn{2}{|c|}{$30 \mathrm{~min}$} & \multicolumn{2}{|c|}{$2 \mathrm{Hr}$} & \multicolumn{2}{|c|}{$5 \mathrm{Hr}$} \\
\hline & $\% \mathrm{ID} / \mathrm{g}$ & \% S.E.M. & $\% \mathrm{ID} / \mathrm{g}$ & \% S.E.M. & $\% \mathrm{ID} / \mathrm{g}$ & \% S.E.M. \\
\hline Blood & 5.5 & 0.3 & 3.1 & 1.4 & 2.7 & 0.3 \\
\hline Heart & 1.9 & 0.9 & 1.9 & 0.2 & 0.8 & 0.3 \\
\hline Lung & 4.8 & 0.4 & 2.3 & 0.3 & 2.0 & 0.3 \\
\hline Thyroid & 2.2 & 0.0 & 2.0 & 0.3 & 1.4 & 0.3 \\
\hline Pancreas & 2.9 & 0.1 & 2.0 & 0.3 & 1.2 & 0.3 \\
\hline Liver & 55.2 & 4.8 & 30.6 & 2.7 & 21.3 & 4.4 \\
\hline Spleen & 27.7 & 3.9 & 12.6 & 1.6 & 6.7 & 1.5 \\
\hline Kidney & 15.1 & 1.6 & 10.3 & 0.3 & 8.6 & 1.5 \\
\hline Stomach & 6.1 & 0.6 & 5.9 & 1.0 & 2.4 & 0.6 \\
\hline Sm intestine & 4.1 & 0.2 & 3.6 & 1.0 & 1.6 & 0.2 \\
\hline Lg intestine & 2.2 & 0.2 & 1.7 & 0.5 & 1.5 & 0.4 \\
\hline Muscle & 1.2 & 0.1 & 0.9 & 0.2 & 0.5 & 0.3 \\
\hline Bone & 1.9 & 0.2 & 1.7 & 0.2 & 0.8 & 0.3 \\
\hline Tumor & 2.8 & 0.3 & 3.7 & 0.2 & 3.9 & 0.1 \\
\hline Tumor: muscle & 2.4 & & 4.4 & & 8.1 & \\
\hline Tumor: bone & 1.5 & & 2.2 & & 4.7 & \\
\hline Tumor:lung & 0.6 & & 1.6 & & 2.0 & \\
\hline Tumor : blood & 0.5 & & 1.2 & & 1.5 & \\
\hline
\end{tabular}

TABLE 2: Radiation dose estimates of reference adults of ${ }^{131} \mathrm{I}-\mathrm{SHH}$ from rats.

\begin{tabular}{lc}
\hline Target organ & $\mathrm{mSv} / \mathrm{MBq}$ \\
\hline Small intestine & $9.65 \times 10^{-02}$ \\
Stomach wall & $9.62 \times 10^{-02}$ \\
Kidneys & $6.34 \times 10^{-01}$ \\
Liver & $4.07 \times 10^{-01}$ \\
Lungs & $8.78 \times 10^{-02}$ \\
Muscle & $4.46 \times 10^{-02}$ \\
Pancreas & $1.73 \times 10^{-01}$ \\
Red marrow & $3.91 \times 10^{-02}$ \\
Osteogenic cells & $9.15 \times 10^{-02}$ \\
Skin & $1.60 \times 10^{-02}$ \\
Spleen & $4.93 \times 10^{-01}$ \\
Thyroid & $1.01 \times 10^{-01}$ \\
Urinary bladder wall & $1.09 \times 10^{-02}$ \\
\hline Total body & $2.95 \times 10^{-01}$ \\
\hline
\end{tabular}

tumor to bone were $2: 1$ and $5: 1$, respectively. Significant uptake of ${ }^{131} \mathrm{I}-\mathrm{SHH}$ was also observed in the liver and kidney. Uptake was also observed in the thyroid and gastrointestinal tract, which may be due in part to dehalogenation that is common with iodinated proteins. Dosimetric studies showed kidneys, liver, and spleen to be the dose-limiting organs. Organ dose estimates are shown in Table 2. Higher absorbed doses may be due to dehalogenation and could potentially be mitigated by blocking absorption of free iodine in a clinical setting.
3.4. Gamma Scintigraphy. Planar imaging studies were conducted with ${ }^{131} \mathrm{I}-\mathrm{SHH}$ to test the potential of imaging PTCH1 receptor expression in a rat model of breast cancer. Fisher rats bearing tumor xenografts of the cell line 13762, a chemically induced rat breast cancer line, were injected with $250 \mu \mathrm{Ci}$ of ${ }^{131} \mathrm{I}-\mathrm{SHH}$. Planar scintigraphy was conducted at $30 \mathrm{~min}, 2,5$, and 24 hours. Studies were performed with iodinated BSA as a control for nonspecific uptake. Tumor accumulation of the tracer was observed at $30 \mathrm{~min}$ and increased up to 5 hours. As shown in Figure 5, the tumor is clearly visualized in the rat injected with ${ }^{131} \mathrm{I}$ $\mathrm{SHH}$, but absent in the animal injected with ${ }^{131} \mathrm{I}$-BSA. Plasma dehalogenation is also observed, with appearance of radioiodine uptake in the thyroid and stomach visualized at 2 hours and increasing on later images. The thyroid, liver, and stomach were also visualized on the animal injected with ${ }^{131}$ I-BSA, further suggesting that the uptake in these organs is due to free iodine that is a result of dehalogenation of the iodinated protein.

\section{Discussion}

Our findings show that expression of the $\mathrm{PTCH}-1$ receptor is increased in breast cancer cells with canonical $\mathrm{HH}$ signaling and that surface PTCH-1 receptor expression is decreased upon treatment with the SMO inhibitor cyclopamine. This decrease correlated to a decrease in uptake of ${ }^{131} \mathrm{I}-\mathrm{SHH}$. These studies are in agreement with previous studies that report direct gene regulation of PTCH-1 by Gli-1 [26] and correlation of Gli-1 activity to PTCH-1 expression [1, 27]. Furthermore, treatment of cancer cells with small molecule 


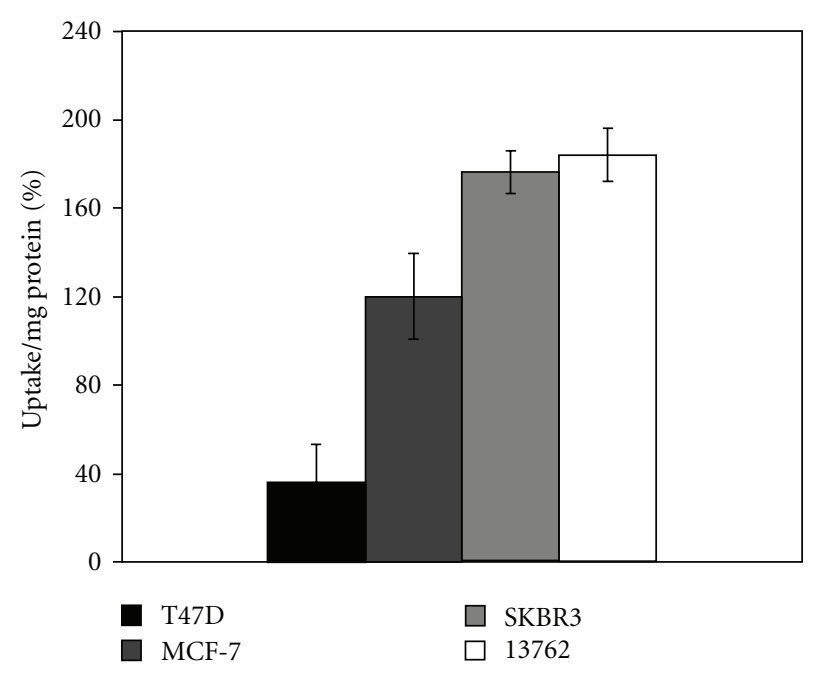

(a)

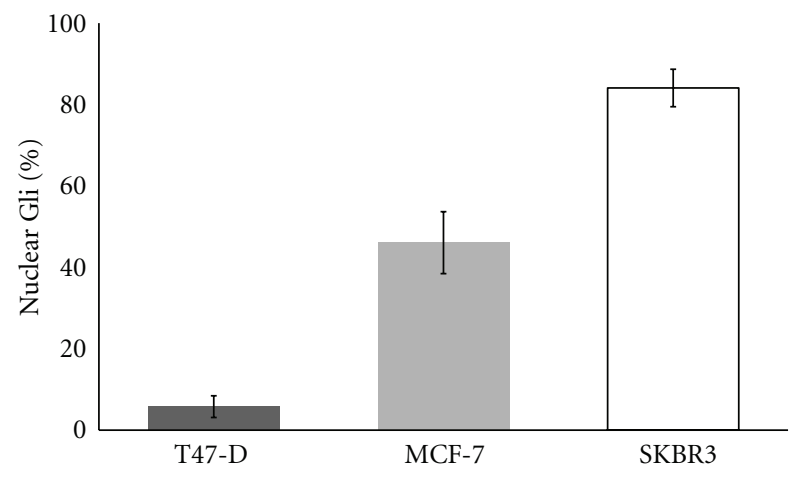

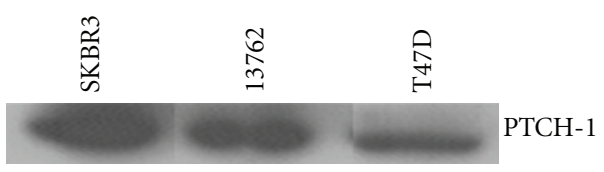

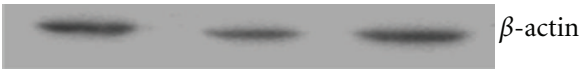

(b)

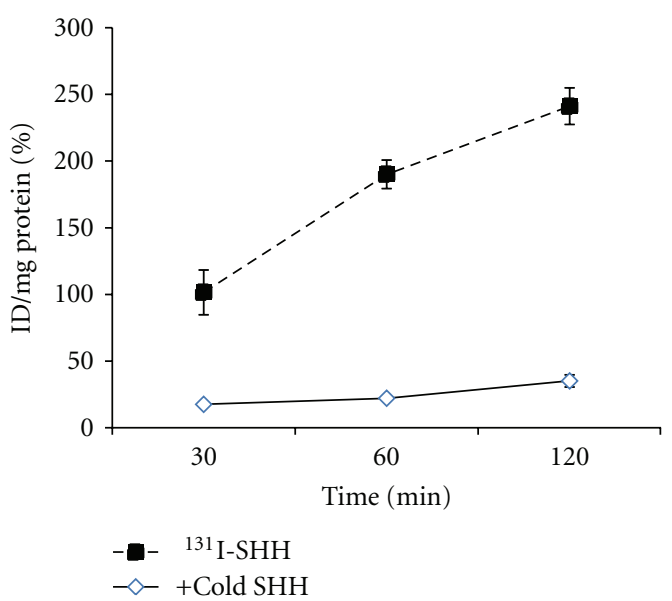

(d)

Figure 2: (a) Cellular uptake of ${ }^{131} \mathrm{I}-\mathrm{SHH}$ in breast cancer cell lines at one hour. Data is represented as the \% injected dose (cpm (cells)/cpm (media))/mg protein. (b) Western blot showing expression of PTCH-1 in breast cancer cell lines. Cellular uptake of ${ }^{131} \mathrm{I}-\mathrm{SHH}$ is correlated with expression of the PTCH-1 receptor. (c) Nuclear Gli-1 expression in breast cancer cell lines. Data is expressed as number of cells with intense nuclear Gli-1 staining. (d) Time course showing increased accumulation of ${ }^{131} \mathrm{I}-\mathrm{SHH}$ in SKBR3 cancer cells with time. Uptake was blocked by 100-fold excess cold SSH.

inhibitors of SMO, which block canonical HH signaling, was shown to decrease PTCH-1 mRNA expression [28].

These studies suggest that binding of radiolabeled $\mathrm{HH}$ to surface PTCH-1 receptors can differentiate tumors with active ligand-dependent $\mathrm{HH}$ signaling, and this feature can be used to image hedgehog activity in tumors. Preliminary imaging studies show that ${ }^{131} \mathrm{I}-\mathrm{SHH}$ is capable of in vivo delineation of breast tumors with high $\mathrm{HH}$ signaling. In these preliminary imaging studies using ${ }^{131} \mathrm{I}-\mathrm{SHH}$ we find that in addition to tumor uptake, ${ }^{131} \mathrm{I}-\mathrm{SHH}$ exhibited high uptake in the spleen and gastrointestinal organs. This uptake potentially arises from deiodination of the tracer as high gastrointestinal uptake was also observed with an iodinated BSA control protein [29]. Furthermore, HH signaling has been shown to increase activity of deiodinases [30], which could potentially increase dehalogenation of ${ }^{131}$ I-labeled compounds in tumors with active $\mathrm{HH}$ signaling. Higher absorbed doses in the intestines, liver, and spleen may be due to dehalogenation and could potentially be mitigated by blocking absorption of free iodine in a clinical setting. It is common to use saturated potassium iodide solution (SSKI) to prevent radiation exposure to thyroid and stomach due to deiodination in clinic settings. However, we cannot rule out possible specific uptake of ${ }^{131} \mathrm{I}-\mathrm{SHH}$ in the GI-tract as there are reports of low-level PTCH-1 expression in normal epithelia in the intestine and liver [31]. Likewise, low-level PTCH-1 expression has also been reported in lymphocytes and follicular dendritic cells present in the spleen [32] during immune responses.

While ligand-dependent hedgehog signaling has been reported in breast cancer and numerous other cancers, heterozygous mutations affecting the membrane receptor 


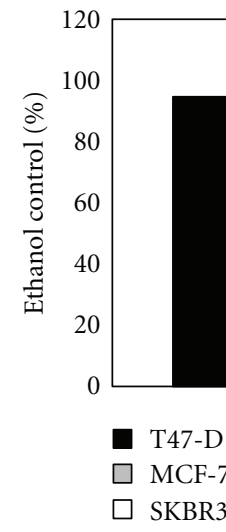

(a)

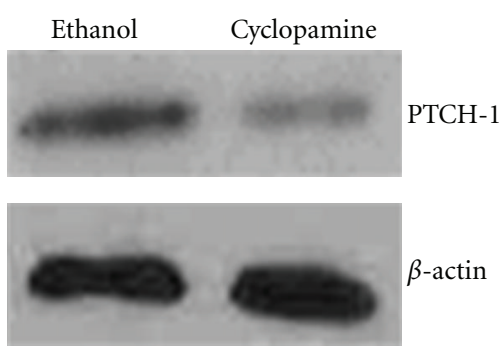

SKBR3
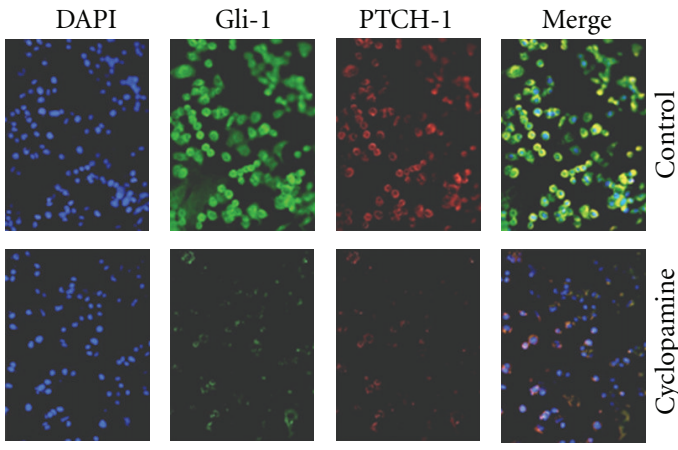

(b)

(c)

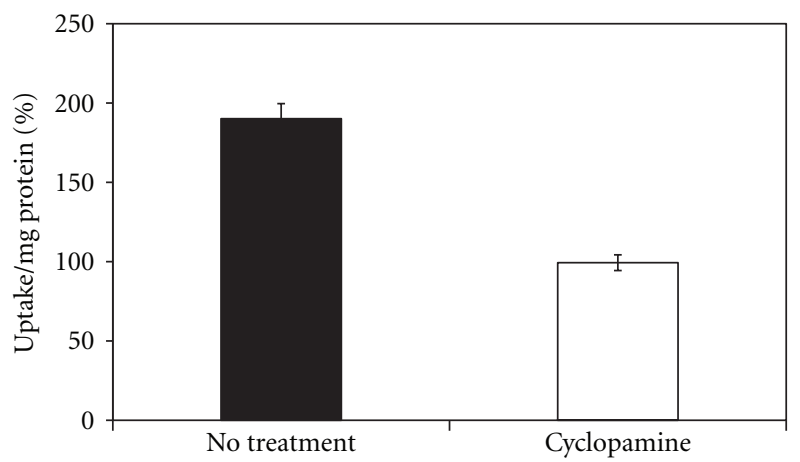

(e)

Figure 3: (a) MTT assay showing decrease in proliferating cells after treatment with $20 \mu \mathrm{M}$ cyclopamine for 48 hours. Data is expressed as $\%$ of control (ethanol treatment only). (b) Western blot showing decrease in PTCH-1 expression in SKBR3 cells treated with $20 \mu \mathrm{M}$ cyclopamine as compared to cells treated with ethanol only. (c) Immunofluorescence showing decrease in PTCH-1 and Gli-1 (nuclear and cytoplasmic) 24 hours after treatment with cyclopamine. (d) Scatchard analysis of ${ }^{131}$ I-SHH binding to the surface of SKBR3 cell lines with and without treatment with $10 \mu \mathrm{M}$ cyclopamine. There is a 5-fold decrease in surface PTCH-1 receptor expression 48 hours after treatment. (e) Reduced cellular uptake of ${ }^{131} \mathrm{I}-\mathrm{SHH}$ in the PTCH-1 receptor positive breast cancer cell line SKBR3 with and without treatment with the HH inhibitor cyclopamine. 


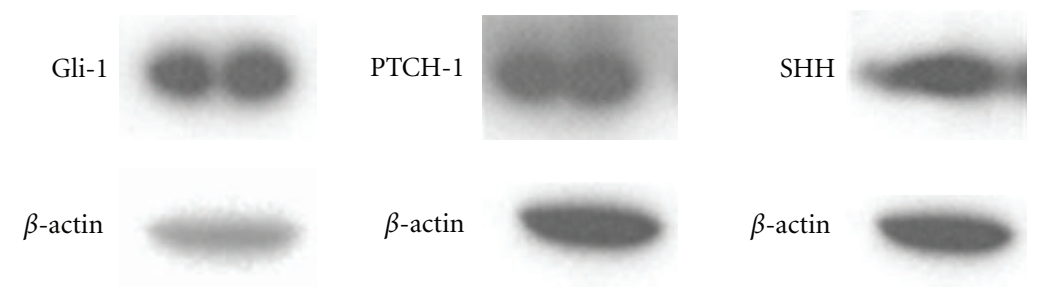

FIGURE 4: Western blot showing strong expression of SHH, PTCH-1, and Gli-1 in 13762 cells. $\beta$-actin is included as a control for protein level.

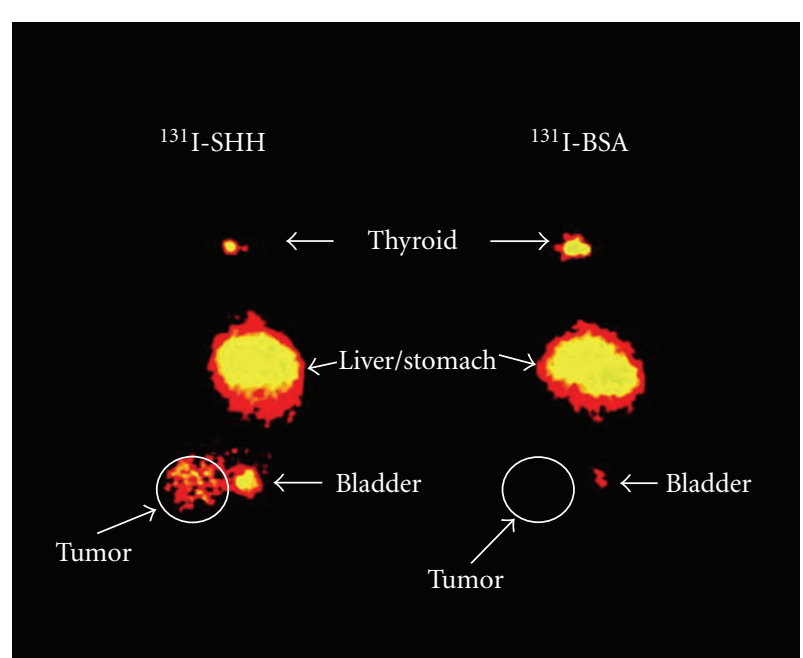

FIGURE 5: Planar image of Fischer 344 rats bearing breast cancer xenografts approximately 2 hours after injection of ${ }^{131} \mathrm{I}-\mathrm{SHH}$ or ${ }^{131} \mathrm{I}$ BSA. Tumor accumulation of the tracer is only observed in the rat injected with ${ }^{131} \mathrm{I}-\mathrm{SHH}$. The thyroid, stomach, and liver are also visible in both animals.

PTCH-1 have been directly linked to carcinogenesis in basal cell carcinoma and neural tumors $[1,2]$. In many cases, these mutations result in truncation of the $\mathrm{PTCH}-1$ receptor and loss of the SMO-binding inhibitory domain. However, in some cases the $\mathrm{N}$-terminal extracellular ligand-binding domain is still expressed [33]. Therefore, while ${ }^{131} \mathrm{I}-\mathrm{SHH}$ was shown to detect canonical $\mathrm{HH}$ activation in our studies, it is still unclear whether this method could also be used to determine hedgehog activation that results from PTCH-1 inactivating mutations.

\section{Conclusions}

Our data suggests that surface PTCH-1 receptor expression is correlated to canonical $\mathrm{HH}$ activity, and its expression is downregulated by small molecule inhibitors of $\mathrm{HH}$ signaling. We propose that radiolabeled $\mathrm{SHH}$ derivatives can be used to detect active $\mathrm{HH}$ signaling by noninvasive imaging. Furthermore, radiolabeled $\mathrm{SHH}$ derivatives may provide a method to determine in vivo response to hedgehog-targeted therapies.

\section{Acknowledgments}

This work was supported by the National Institutes of Health/National Cancer Institute Grant RO1 CA138230-01.

\section{References}

[1] E. B. Harmon, A. H. Ko, and S. K. Kim, "Hedgehog signaling in gastrointestinal development and disease," Current Molecular Medicine, vol. 2, no. 1, pp. 67-82, 2002.

[2] A. E. Bale and K. P. Yu, "The hedgehog pathway and basal cell carcinomas," Human Molecular Genetics, vol. 10, no. 7, pp. 757-762, 2001.

[3] D. M. Berman, S. S. Karhadkar, A. Maitra et al., "Widespread requirement for Hedgehog ligand stimulation in growth of digestive tract tumours," Nature, vol. 425, no. 6960, pp. 846851, 2003.

[4] D. N. Watkins and C. D. Peacock, "Hedgehog signalling in foregut malignancy," Biochemical Pharmacology, vol. 68, no. 6, pp. 1055-1060, 2004.

[5] S. P. Thayer, M. P. di Magliano, P. W. Heiser et al., "Hedgehog is an early and late mediator of pancreatic cancer tumorigenesis," Nature, vol. 425, no. 6960, pp. 851-856, 2003.

[6] X. Ma, T. Sheng, Y. Zhang et al., "Hedgehog signaling is activated in subsets of esophageal cancers," International Journal of Cancer, vol. 118, no. 1, pp. 139-148, 2006.

[7] J. W. Theunissen and F. J. De Sauvage, "Paracrine hedgehog signaling in cancer," Cancer Research, vol. 69, no. 15, pp. 60076010, 2009.

[8] J. Sims-Mourtada, J. G. Izzo, J. Ajani, and K. S. C. Chao, "Sonic Hedgehog promotes multiple drug resistance by regulation of drug transport," Oncogene, vol. 26, no. 38, pp. 5674-5679, 2007.

[9] J. Sims-Mourtada, J. G. Izzo, S. Apisarnthanarax et al., "Hedgehog: an attribute to tumor regrowth after chemoradiotherapy and a target to improve radiation response," Clinical Cancer Research, vol. 12, no. 21, pp. 6565-6572, 2006.

[10] Z. Shafaee, H. Schmidt, W. Du, M. Posner, and R. Weichselbaum, "Cyclopamine increases the cytotoxic effects of paclitaxel and radiation but not cisplatin and gemcitabine in hedgehog expressing pancreatic cancer cells," Cancer Chemotherapy and Pharmacology, vol. 58, no. 6, pp. 765-770, 2006.

[11] J. M. Leonard, H. Ye, C. Wetmore, and L. M. Karnitz, "Sonic Hedgehog signaling impairs ionizing radiationinduced checkpoint activation and induces genomic instability," Journal of Cell Biology, vol. 183, no. 3, pp. 385-391, 2008.

[12] P. W. Ingham and A. P. McMahon, "Hedgehog signaling in animal development: paradigms and principles," Genes and Development, vol. 15, no. 23, pp. 3059-3087, 2001. 
[13] L. Ruel, R. Rodriguez, A. Gallet, L. Lavenant-Staccini, and P. P. Thérond, "Stability and association of Smoothened, Costal2 and fused with Cubitus interruptus are regulated by Hedgehog," Nature Cell Biology, vol. 5, no. 10, pp. 907-913, 2003.

[14] J. W. Yoon, Y. Kita, D. J. Frank et al., "Gene expression profiling leads to identification of GLI1-binding elements in target genes and a role for multiple downstream pathways in GLI1-induced cell transformation," The Journal of Biological Chemistry, vol. 277, no. 7, pp. 5548-5555, 2002.

[15] P. Dai, H. Akimaru, Y. Tanaka, T. Maekawa, M. Nakafuku, and S. Ishii, "Sonic hedgehog-induced activation of the Gli1 promoter is mediated by GLI3," The Journal of Biological Chemistry, vol. 274, no. 12, pp. 8143-8152, 1999.

[16] M. Kubo, M. Nakamura, A. Tasaki et al., "Hedgehog signaling pathway is a new therapeutic target for patients with breast cancer," Cancer Research, vol. 64, no. 17, pp. 6071-6074, 2004.

[17] Y. Xuan and Z. Lin, "Expression of Indian Hedgehog signaling molecules in breast cancer," Journal of Cancer Research and Clinical Oncology, vol. 135, no. 2, pp. 235-240, 2009.

[18] C. Mas and A. Ruiz i Altaba, "Small molecule modulation of HH-GLI signaling: current leads, trials and tribulations," Biochemical Pharmacology, vol. 80, no. 5, pp. 712-723, 2010.

[19] J. P. Incardona, J. H. Lee, C. P. Robertson, K. Enga, R. P. Kapur, and H. Roelink, "Receptor-mediated endocytosis of soluble and membrane-tethered sonic hedgehog by patched1," Proceedings of the National Academy of Sciences of the United States of America, vol. 97, no. 22, pp. 12044-12049, 2000.

[20] D. J. Yang, K. D. Kim, N. R. Schechter et al., "Assessment of antiangiogenic effect using 99mTc-EC-endostatin," Cancer Biotherapy and Radiopharmaceuticals, vol. 17, no. 2, pp. 233246, 2002.

[21] D. P. Baker, F. R. Taylor, and R. B. Pepinsky, "Purifying the hedgehog protein and its variants," Methods in Molecular Biology, vol. 397, pp. 1-22, 2007.

[22] C. M. Lahorte, C. van de Wiele, K. Bacher et al., "Biodistribution and dosimetry study of 123I-rh-annexin $\mathrm{V}$ in mice and humans," Nuclear Medicine Communications, vol. 24, no. 8, pp. 871-880, 2003.

[23] J. Sims-Mourtada, J. G. Izzo, J. Ajani, and K. S. C. Chao, "Sonic Hedgehog promotes multiple drug resistance by regulation of drug transport," Oncogene, vol. 26, no. 38, pp. 5674-5679, 2007.

[24] D. J. Macey, L. E. Williams, H. B. Breitz, A. Liu, T. K. Johnson, and P. B. Zanzonico, "A primer for radioimmunotherapy and radionuclide therapy," Tech. Rep. 7, AAPM Nuclear Medicine Committee, American Association of Physicists in Medicine, 2001.

[25] Y. J. Chen, J. Sims-Mourtada, J. Izzo, and K. S. C. Chao, "Targeting the hedgehog pathway to mitigate treatment resistance," Cell Cycle, vol. 6, no. 15, pp. 1826-1830, 2007.

[26] M. H. Shahi, M. Afzal, S. Sinha et al., "Regulation of sonic hedgehog-GLI1 downstream target genes PTCH1, Cyclin D2, Plakoglobin, PAX6 and NKX2.2 and their epigenetic status in medulloblastoma and astrocytoma," BMC Cancer, vol. 10, article 614, 2010.

[27] M. Katano, "Hedgehog signaling pathway as a therapeutic target in breast cancer," Cancer Letters, vol. 227, no. 2, pp. 99104, 2005.

[28] G. Shaw and D. M. Prowse, "Inhibition of androgenindependent prostate cancer cell growth is enhanced by combination therapy targeting Hedgehog and ErbB signalling," Cancer Cell International, vol. 8, article 3, 2008.

[29] K. A. Krohn, L. C. Knight, J. F. Harwig, and M. J. Welch, "Differences in the sites of iodination of proteins following four methods of radioiodination," Biochimica et Biophysica Acta, vol. 490, no. 2, pp. 497-505, 1977.

[30] M. Dentice, C. Luongo, S. Huang et al., "Sonic hedgehoginduced type 3 deiodinase blocks thyroid hormone action enhancing proliferation of normal and malignant keratinocytes," Proceedings of the National Academy of Sciences of the United States of America, vol. 104, no. 36, pp. 14466-14471, 2007.

[31] T. Mazumdar, J. DeVecchio, T. Shi, J. Jones, A. Agyeman, and J. A. Houghton, "Hedgehog signaling drives cellular survival in human colon carcinoma cells," Cancer Research, vol. 71, no. 3, pp. 1092-1102, 2011.

[32] R. Sacedón, B. Díez, V. Nuñez et al., "Sonic hedgehog is produced by follicular dendritic cells and protects germinal center B cells from apoptosis," Journal of Immunology, vol. 174, no. 3, pp. 1456-1461, 2005.

[33] J. Li, J. Wang, Y. Liu, and W. Wang, "Analysis of mutation in exon 17 of PTCH in patients with nevoid basal cell carcinoma syndrome," Molecular Biology Reports, vol. 37, no. 1, pp. 359$362,2010$. 


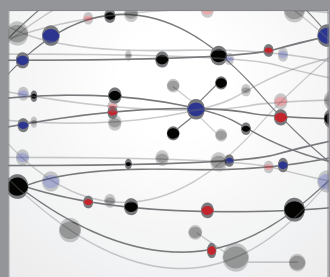

The Scientific World Journal
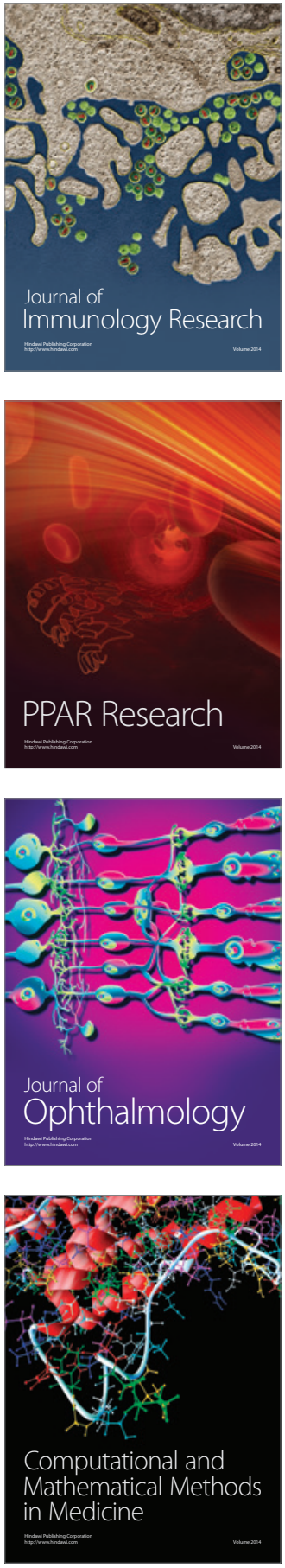

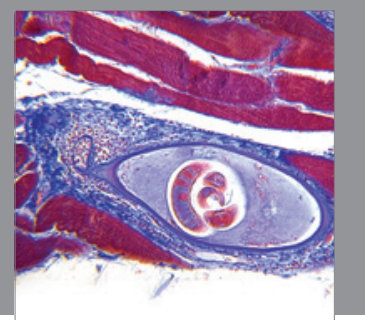

Gastroenterology

Research and Practice
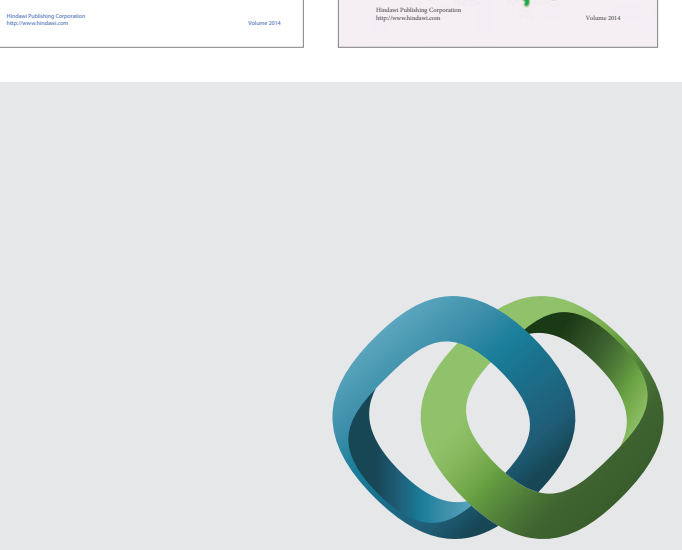

\section{Hindawi}

Submit your manuscripts at

http://www.hindawi.com
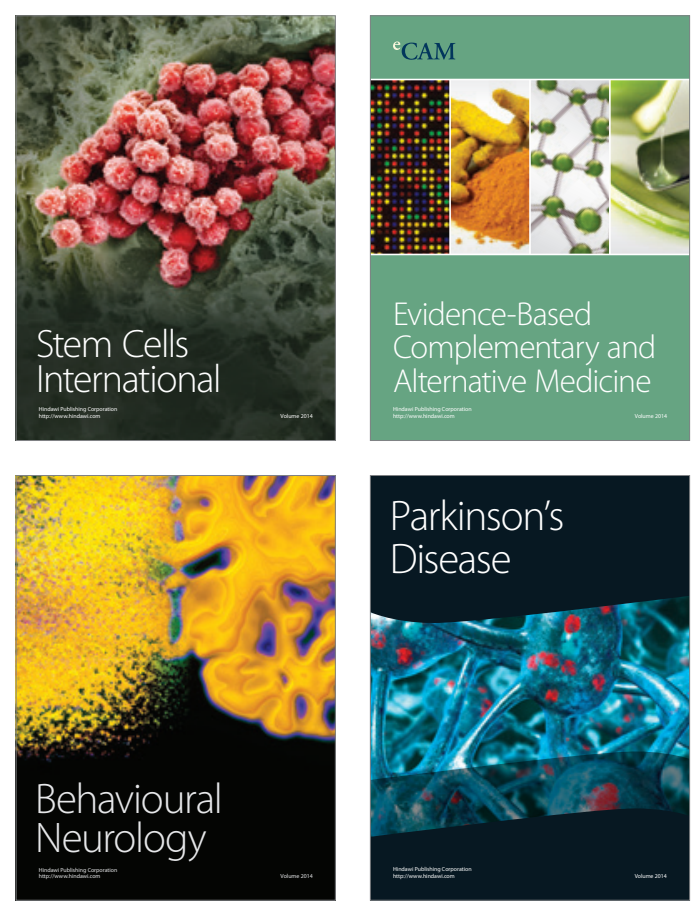

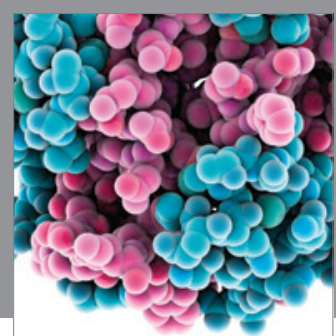

Journal of
Diabetes Research

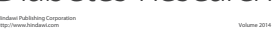

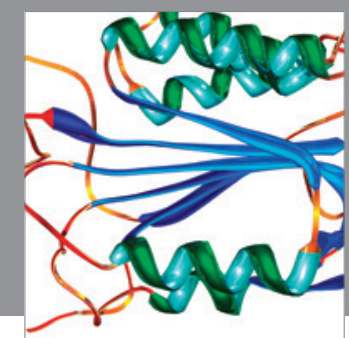

Disease Markers
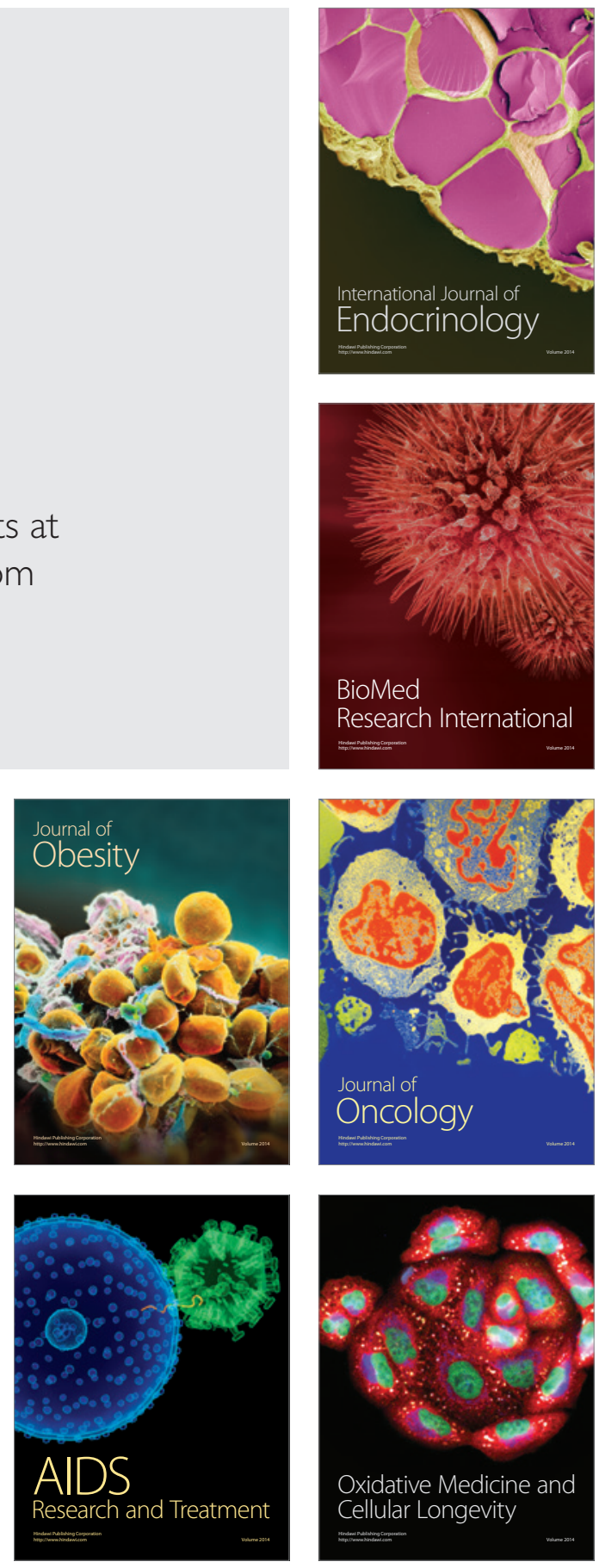